\title{
Research on Environmental Simulation of Team Operational Trials Against
}

\author{
Li Hongkui, Ma Li, Zhang Junbin, and Liu Fei \\ Baicheng weapon test center, Jilin Baicheng, 137001
}

Keywords: Term fighting, against environmental, simulation method.

\begin{abstract}
The paper analyzes the typical combat environment of fighting against the team needed to experience, determine the shooting environment, the environment and the components of the electromagnetic environment, puts forward the simulation method and technical way.
\end{abstract}

\section{Preface}

Dynamic against battlefield environment has an important influence on the result of the operational test. Therefore, we need to analysis the requirement of weapon system, research the typical combat environment, and build the simulation of battlefield environment by using the simulation technology, providing technical support for team operational test.

\section{Soldiers' environment simulation}

In the modern war, the shooting opportunity is reduce in the effective range of weapons and equipment. The target performance for more random and appear in different forms (head of target, chest silhouette, systemic target), distance, length of time, which put forward severe challenges to the quickly response and ability of fast shooting of team. The elements affecting soldiers' environment simulation as follows:

(1) Presence distance of the target

The presence distance of the target is directly related to the gun hit effect and the authenticity of the simulated real shot. To determine the target distance, we should analyze from various angles, and determine comprehensively.

a.The maximum range aiming of sight on the goal

Due to the topography, weather conditions and the influence of many factors, the shooting position of actual combat in the maximum distance of target is limited. The US army analyzed battle in World War II, and found rifle aimed maximum distance to personnel during the day within $400 \mathrm{~m}$ and the vast majority of nighttime within $100 \mathrm{~m}$ in the actual combat.

b.Distance of target detected by soldiers' eye

The detection distance of target is influenced by intensity and angle of light, landform, vegetation, camouflage, the exposure time and movement of a target speed etc. The American institute of human resources had the type of target detection test in the $1970 \mathrm{~s}$. The test choose simple, moderately and complex three kinds of terrain, a 15 degree angle fan area 100, 200, 300m three observation distances, and walking, jogging, running three kinds of speed observation tests have been carried out with the aim to detect in a combat soldier uniform.

There are 751 times in 810 observations observed target successfully, the rates of success $80 \%$. $300 \mathrm{~m}$ distance in complex terrain, and 90 observations are not observed goal at a time. The experiment shows that unless is better (flat), open terrain conditions, actual combat in the macroscopic observable humanoid targets more than $300 \mathrm{~m}$ distance of the success rate is relatively low. Development of U.S. combat command firearms \&production for the naked eye chest round target test, in order to simulate the actual effect, also placed under chest round target shooting simulator. The test results show that in $500 \mathrm{~m}$ distance is found on the target is not a problem, but it's not easy to estimate the distance. Korean War also has reports of humanoid target detection range interval, as shown in table 1. 


\begin{tabular}{ll}
\hline Distance $(\mathrm{m})$ & Condition \\
\hline $15-200$ & All situation \\
$15-150$ & Attack target \\
$50-200$ & Day \\
$15-50$ & Night \\
$15-30$ & Night and concave-convex terrain \\
\hline
\end{tabular}

c.Practice gun firing distance

In actual combat rifle firing distance is usually shorter than observation and the observed target distance, this is because the practice in order to improve the hit ratio or for other reasons, sometimes making them closer to after the shooting. So the practice of gun firing distance is more meaningful. Usually adopt two ways to determine the actual combat of firing distance, one is a research of staff, the other is from the field in the documentary. Johns Hopkins University had two surveys, one is firing distance during the day in the Korean War, the other is the war ii in Europe, the Pacific and north Korea for firing distance under different visibility in the field, the results are shown in figure 1.

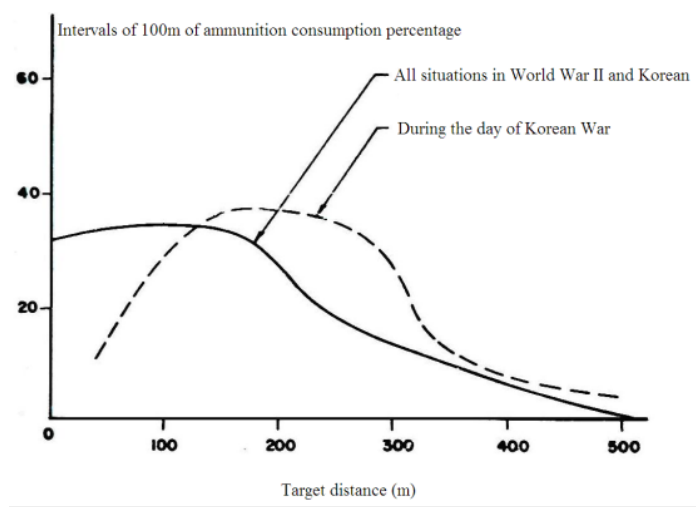

Fig. 1. in the World War II and the Korean War rifle fire different distance of percentage

From Europe and the Pacific during World War II, the Korean war, Vietnam war battlefield documentary analysis can rifle firing distance, draw out the curve shown in figure 2.

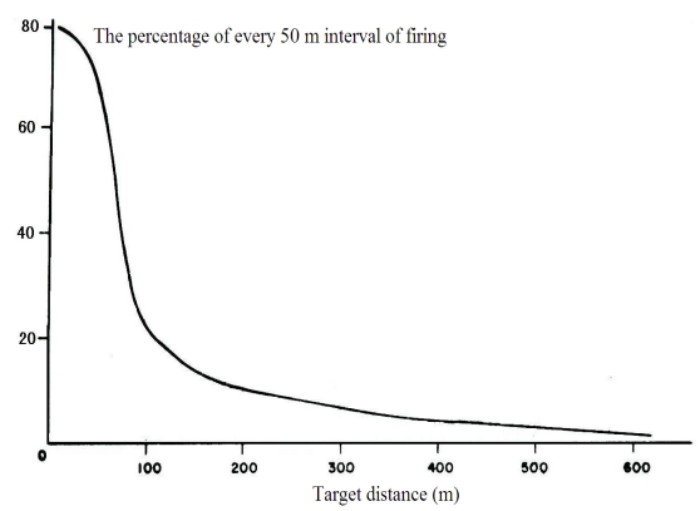

Fig. 2. in the World War II, the Korean War and Vietnam War, the firing distance distribution estimation

The results and the observation and survey of infantry in the Korean War in the conclusion obtained are consistent, as shown in table 2.

Table 2 the firearms use maximum distance estimation in the Korean War

\begin{tabular}{cc}
\hline Distance $(\mathrm{m})$ & Condition \\
\hline Nearest to 400 & All of the squad \\
Approximation 300 & Browning "standard" the maximum range of automatic rifle fire \\
Approximation 200 & The "effective" distance of small arms fire \\
\hline
\end{tabular}




\begin{tabular}{cc}
\hline $\begin{array}{c}\text { Approximation } 150 \\
\text { Nearest to } 50\end{array}$ & $\begin{array}{c}\text { The biggest decision attack distance } \\
\text { The distance of attack with the Chinese army }\end{array}$ \\
\hline
\end{tabular}

Through the study of by small arms to kill your soldiers in the war, also be helpful to determine the small arms fire distance, table 3 is a few times battle casualties' statistical relationship with distance. Distance can be seen from the table in the small arms of casualties than target distance and distance is short, the hit probability and distance relationship can better explain the phenomenon.

Table 3 distance of small-arms effective kill

\begin{tabular}{|c|c|c|c|c|c|c|c|c|}
\hline Source of data & \multicolumn{2}{|c|}{$\begin{array}{l}\text { World War II, } \\
\text { New Georgia } \\
\text { Island and } \\
\text { Burma }\end{array}$} & \multicolumn{2}{|c|}{$\begin{array}{l}\text { Bougainville } \\
\text { Island }\end{array}$} & \multicolumn{3}{|c|}{ Turkey in The Korean War } & $\begin{array}{l}\text { The } \\
\text { Vietnam } \\
\text { War }\end{array}$ \\
\hline $\begin{array}{l}\text { arms killer } \\
\text { investigation }\end{array}$ & \multicolumn{2}{|c|}{219} & \multicolumn{2}{|c|}{459} & \multicolumn{3}{|c|}{257} & 4980 \\
\hline \multirow{2}{*}{$\begin{array}{l}\text { Various kinds of } \\
\text { guns kill number }\end{array}$} & Rifle & Stutterer & Rifle & Stutterer & Rifle & Stutterer & $\begin{array}{l}\text { Pistol or } \\
\text { tommy gun }\end{array}$ & Rifle \\
\hline & 93 & 115 & 339 & 121 & 149 & 59 & 28 & 991 \\
\hline Execution distance & $\begin{array}{l}68 \% \\
\text { in } \\
70 \mathrm{~m}\end{array}$ & $\begin{array}{c}65 \% \text { in } \\
70 \mathrm{~m}\end{array}$ & $\begin{array}{c}80 \% \text { in } \\
70 \mathrm{~m}\end{array}$ & $\begin{array}{c}86 \% \text { in } \\
70 \mathrm{~m}\end{array}$ & $\begin{array}{c}\text { Average } \\
112 \mathrm{~m}\end{array}$ & $\begin{array}{c}\text { Average } \\
71 \mathrm{~m}\end{array}$ & & $\begin{array}{c}\text { Average } \\
73 \mathrm{~m}\end{array}$ \\
\hline
\end{tabular}

Through the above analysis we can sum up the practice small arms fire and caused most of the casualties are within $100 \mathrm{~m}$, only a tiny part in the $300 \mathrm{~m}$ away. Although this conclusion by statistical data of war decades ago, but still apply to the modern infantry combat. Although the performance of the rifle has greatly improved and improve, but the basic operational mode and there is not much changes, especially the use of all kinds of tanks and armored vehicles, and the increasing proportion of urban warfare, combat may sometimes shorter distance. As a result of the aiming system improvement, sniper rifle range has been able to reach $1000 \mathrm{~m}$; the situation should be taken into account when considering the target distance, according to the different tactics, combined with the analysis of the above data, can draw the percentage of the number of different distance targets, as shown in figure 3.

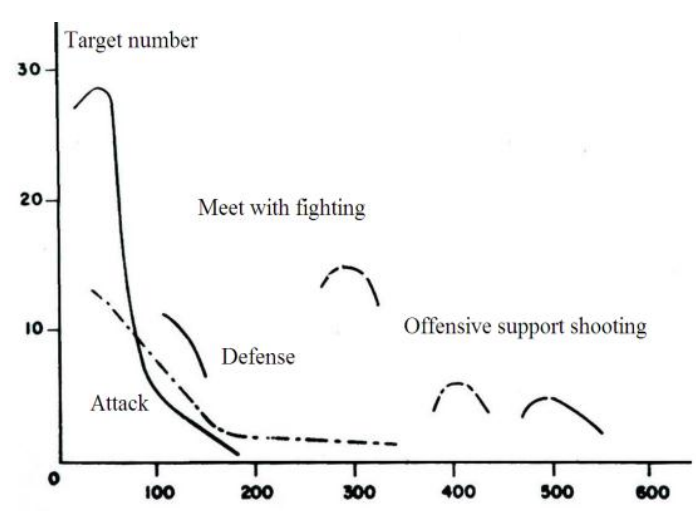

Fig. 3. target distance distribution curve

(2) The number of target

a.At first, want to consider the characteristics of tactical test burden. As a defensive and offensive tactics in combat has bigger difference in nature, defensive fights as a class usually 
several times to resist the enemy, and offensive operations is very few, so the defense needs the number of test places is larger.

b.To fight in all possible target distance. $400 \mathrm{~m}$ distance to the shooting position for rifle dozens of meters are wiped out for the effective range of the target, so often in the far distance, middle and last three layout target. With combat usually decorate in the distance, and a variety of different perspectives on target.

c.Simulation actual combat shooting intensity as much as possible. Such as defense battle is likely to attack the enemy repelled from two directions at the same time, target decorate to simulate the enemy's attack formation, to ensure adequate quantity.

d.Considering from the safety, feasibility of test in the number of targets. Defensive fights for a class of shooting at the same time, so the number of targets demand is bigger. A combat range due to consider fire safety, only for a person to shoot test at the same time, so the small number of targets.

e.The number of targets is not more than a combat mission number of targets of ammunition.

(3) Show time of the target

Identify the target display time is a complex problem. Usually want to consider the factors of four aspects: 1 . The operational way; 2 . Complete a shooting time; 3 . Observation to determine the time require for a goal; 4 . He found himself become after the shooting target decided to hide the reaction time, after considering these four factors to determine the target display of time. For offensive operations, due to the target from foxholes, so target exposure time is usually long, only when the target hit or by violently suppressed. Rising between defense and encounters the target time to consider other factors, For infantry, complete a shot is usually only a few seconds, there's still not see more authoritative research reports, but according to experience, for the aim to shoot, fastest need only 1 to 2 seconds, aimed shot only need 3-5 seconds. When he discovered he had become the target of being shot, decided to hide the reaction time is usually short, only 1 to 2 seconds.

Due to the continuous development of tactical, operational situation of modern warfare could change. Appeared from the target time to see, should be less than the above time. In general, according to the rate of hundreds of meters, considering the weight and the battlefield environment, at the time of impact, a jump 20-30 m, the average time spent $10 \mathrm{~s}$. in defense, target display time shorter.

(4) Time of shots for the time of target display

Experimental results show that the target show time for 10 seconds, shooting 2-3, have ideal hit probability, in 3 to 5 seconds to shoot one the best results. So in target shooting number display time should be 2-3 times.

From the security considerations, usually adopt laser simulated shooting, the cover of the target simulation target simulation personnel movement. Show hidden targets simulated target is mainly composed of fixed targets, moving targets of Cain, can simulate a single target (target head, chest silhouette, and systemic target) and cluster target, running target, etc.

\section{Electromagnetic Environment Simulation}

The battlefield electromagnetic environment is also influenced by battle style, battlefield scale, the restriction of war process and specifications. In team operations, battlefield electromagnetic environment mainly depends on the following basic elements:

(1) The number of both sides electronic devices;

(2) The use of both sides electronic equipment solution; 
(3) both sides of the complexity of the electronic equipment and characteristics of the radiation signal;

(4) Both sides degree of dependence on electronic equipment;

(5)The analysis and grasp of battlefield electromagnetic environment and requirements.

Based on both sides electronic equipment quantity and level are equal in the offensive battle , and the numbers of enemy electronic equipment are 2-3 times to us in the defense battle, having the application level. Numbers of our electronic devices and the application level can be used for simulating the entire battlefield electromagnetic environment.

Electromagnetic environment simulation equipment is mainly composed of radio Beijing simulation subsystem, signal simulation subsystem and the monitoring and evaluation subsystem.

\section{Conclusion}

The environmental elements and simulation method of team combats tests are discussed in this paper, leading the conclusion as follows:

(1) Determining the typical patterns of team combats and the use of equipment requirements;

(2) Determining the elements of shooting environment, personnel environment and electromagnetic interference environment etc., putting forward the corresponding simulation method and technical way.

\section{Reference}

[1] United States Army Infantry Board Fort Benning, Georgia 3190 "Infantry Weapons Test Methodology Study: Integrated Operation Test and Analysis Procedures for Small Weapons Systems Evaluation".

[2] HUANG Wenqing. Combat simulation theory and technology. Beijing: National Defense Industry Press, 2011. 